\title{
Comment on: Cosmetic procedures among youths: A SURVey of Junior College AND MEDical STUDENTS IN SINGAPORE: PART 2
}

Singapore Med J 2015; 56(1): 65 doi: 10.11622/smedj.2015012

Dear Sir,

We read with great interest $\mathrm{Ng}$ et al's ${ }^{(1)}$ reply to our letter. It is true that Javo and Sørlie's ${ }^{(2)}$ study cohort did have differences in age and maturity, but the study used the method of randomisation in selecting the participants in order to reduce the effect of age and maturity as confounding factors. On the other hand, a direct comparison between junior college and medical school students was drawn in Ng et al's study. ${ }^{(3)}$ Besides that, Javo and Sørlie's $\mathbf{s}^{(2)}$ study cohort only included females, making it difficult to compare with $\mathrm{Ng}$ et al's study, ${ }^{(3)}$ which included both genders, as different genders have different perceptions toward cosmetic surgery. ${ }^{(4)}$ We would also like to note that according to a statement by the Ministry of Education, Singapore, universal education (i.e. compulsory education) is only provided up to secondary school, ${ }^{(5)}$ after which the levels of education can differ greatly. These differences can be seen in the Statistics Singapore March 2013 report, "Educational Profile of Singapore Resident Non-Students, 2002-2012". ${ }^{(6)}$ The study sample by $\mathrm{Ng}$ et $\mathrm{al}^{(3)}$ focused on junior college and medical school students (i.e. after secondary school).

Yours sincerely,

Shunjie Chua ${ }^{1}$, Jing $\underline{\mathrm{Li}}^{2}$

${ }^{1}$ Duke NUS Graduate Medical School, Singapore, ${ }^{2}$ Department of Rheumatology, Jiangsu University Affiliated Hospital, Jiangsu, China. chuashunjie@nus.edu.sg

\section{REFERENCES}

1. Ng JH, Yeak S, Phoon N, Lo S. Authors' reply: Comment on: Cosmetic procedures among youths: survey of junior college and medical students in Singapore. Singapore Med J 2014; 55:552.

2. Javo IM, Sørlie T. Psychosocial predictors of an interest in cosmetic surgery among young Norwegian women: a population-based study. Plast Surg Nurs 2010; 30:180-6.

3. Ng JH, Yeak S, Phoon N, Lo S. Cosmetic procedures among youths: a survey of junior college and medical students in Singapore. Singapore Med J 2014; 55:422-6.

4. Sarwer DB, Pruzinsky T, Cash TF, et al. Psychological Aspects of Reconstructive and Cosmetic Plastic Surgery: Clinical, Empirical, and Ethical Perspectives. Philadelphia: Lippincott, Williams \& Wilkins, 2006.

5. Ministry of Education, Singapore. Compulsory Education. Available from: http://www.moe.gov.sg/initiatives/compulsory-education/. Accessed October 29, 2014.

6. ZW Teo. Educational Profile of Singapore Resident Non-Students, 2002-2012. In: Statistics Singapore Newsletter [online]. Available from: http://www. singstat.gov.sg/Publications/publications_and_papers/education_and_literacy/ssnmar13-pg1-7.pdf. Accessed October 29, 2014. 